\title{
Tem um queniano correndo entre nós: atletismo e migração no Brasil
}

CDD. 20.ed. 796.42

796.5

\section{Carlos RIBEIRO* \\ Hugo LOVISOLO** \\ Alberto GOMES* \\ Andrezza SANT'ANNA* \\ *Universidade Gama \\ Filho. \\ *Universidade do Esta- \\ do do Rio de Janeiro.}

\section{Resumo}

0 objetivo da pesquisa foi analisar a movimentação migratória de esportistas estrangeiros do atletismo, sobretudo os de nacionalidades africanas, face ao seu sucesso em corridas de rua disputadas nas grandes cidades brasileiras. Focamos nossas análises na fala dos técnicos brasileiros de nível internacional que trabalham ou não com este grupo. Os resultados demonstram que os técnicos que treinam os atletas estrangeiros são contrários as normas reguladoras em vigor e que limitam a participação destes. Os técnicos centrados em atletas nacionais defendem as normas estabelecidas pela entidade responsável pelo esporte no país. Como conclusão, consideramos que um esporte individual como o atletismo que se estrutura à margem da identidade clubística, parece estar operando por parte de seus protagonistas sob o guarda chuva protetor do nacionalismo em que o atleta local deve ser defendido mediante reserva do mercado, contra a participação de atletas estrangeiros, sobretudo, na figura dos africanos.

Palavras-Chave: Atletismo; Migração; Nacionalismo.

\section{Introdução}

A movimentação migratória de atletas ao redor do mundo tem sido um fenômeno social estudado ${ }^{1-2}$. No Brasil, os estudos sobre esta temática têm sido consistentes e, de forma geral, focam seus objetivos em jogadores de futebol que deixam o país para atuar em outros países e sua difícil entrada neste mercado de trabalho internaciona ${ }^{3-5}$. O jornalismo esportivo também tem realizado séries televisivas centrada nos atletas de futebol que jogam no estrangeiro. $\mathrm{O}$ material é rico e diversificado. Porém, se estes estudos focam nas narrativas de atletas, êxitos e agruras, em circuitos internacionais, alguns pouco conhecidos dos expectadores brasileiros, ainda são raros os estudos que focam nos atletas que vem para treinar, competir e viver em nosso país, principalmente em outros esportes.

Queremos compreender como se dá o processo inverso, quando nosso país recebe esportistas estrangeiros e quais as representações que estas entradas, estadias e participações nas corridas de rua tem perante aos principais atores envolvidos neste processo, tais como os técnicos que preparam este grupo de atletas e que atuam como captadores e formadores desta mão-de-obra especializada. A partir disto queremos saber:

Como se dão as tensōes do mercado de trabalho de corridas de rua no Brasil?

Como os técnicos brasileiros compreendem a participação de atletas estrangeiros nas corridas de rua no Brasil?

Estamos escrevendo sobre um mercado que tem crescido significativamente no Brasil tanto em termos de praticantes, corridas homologadas e premiaçōes. Para termos um exemplo, o número de praticantes encontra-se em cerca de 4,5 milhões ${ }^{6}$ e o número de corridas homologadas no Estado de São Paulo saltou de 11 no ano de 2001 para 287 em 20107. Já o valor da premiação da corrida de São Silvestre somou 176.000,00 reais (perto de 100.00 dólares) em 20118.

Os atletas advindos do continente africano, sobretudo os quenianos, entram nas competições de corrida como favoritos, muito por conta das premiaçōes e do nível técnico não tão superior, obtendo melhores 
resultados, troféus, premiações. Consequentemente passam a ser requisitados nas provas mais famosas pelos organizadores, tais como São Silvestre, Maratona de São Paulo e a Volta da Pampulha.

O objetivo desta pesquisa é compreender a movimentação migratória de esportistas estrangeiros nas corridas de rua no Brasil. É a partir das restriçōes impostas aos estrangeiros sobre sua participação em competiçôes no Brasil nos últimos anos pelas organizaçôes esportistas que iniciaremos nossa pesquisa, pois percebemos que esta é frequentemente enunciada no espaço de interação de dirigentes, técnicos e atletas, afetando o cotidiano dos treinamentos e competições.

A hipótese de nosso estudo é de que a intensificação das movimentações migratórias esportivas ao redor do mundo geram conflitos de interesse entre as confederações locais, os atletas estrangeiros e seus agentes. Para justificar medidas de restrição ou impedir que elas aconteçam, os principais envolvidos no Brasil se prontificam a perpetuar o discurso do nacionalismo e da reserva de mercado como guarda-chuva protetor.

Focaremos na representação dos estrangeiros advindos do continente africano, face ao sucesso destes em corridas de rua disputas nas cidades brasileiras. Reportamos-nos aos africanos, pois estes são considerados como os melhores atletas de corrida de longa distância do mundo. Especificamente, aqueles advindos do leste da África tais como a Etiópia, o Quênia e a Tanzânia, países com longa tradição de bons resultados internacionais neste esporte, sobretudo nos últimos 15 anos.
As revistas especializadas tendem a reforçar os treinamentos (em grandes altitudes), as estratégias (cansando os adversários com sprints nos finais das corridas) e as formas de correr dos africanos (preferencialmente em gramas ou chão de terra batida), sobretudo os corredores nascidos no Quênia ${ }^{a}$. Neste ambiente o sucesso segue a fórmula, o "modus operandi” dos atletas advindos deste país .

Uma das justificativas para tais resultados é o fato destes atletas serem privilegiados na questão geográfica, pois tem a oportunidade desde os primeiros anos neste esporte de treinarem em altitudes elevadas (acima de 2.000 metros do nível do mar) o que oportunizaria uma série de benefícios, tais como um melhor desenvolvimento da capacidade pulmonar, o que nas corridas de rua é fundamental?

Em nossa pesquisa problematizamos questôes sobre o processo de participação de atletas estrangeiros e uma suposta forma de reserva de mercado no Brasil, visando proteger os atletas nacionais que aqui competem. Observaremos como destaque as competiçôes de rua consideradas de longa distância (acima de 5.000 metros) e os atletas advindos de países considerados de elite deste esporte. Concentraremos-nos nestas corridas de rua, pois estas terem oferecido valores financeiros vantajosos com um calendário permanente e variado ao longo do ano. Tal fato possibilita que a cada final de semana exista uma prova de nível técnico razoável acontecendo em uma grande capital brasileira, pagando cerca de cinco mil reais para as primeiras colocaçõesc .

\section{As movimentações migratórias no atletismo}

Comparado a outros circuitos internacionais esportivos tais como o boxe e o tênis, o atletismo também se destaca como esporte individual que propicia ganhos financeiros interessantes em diversos países para atletas e treinadores dispostos a viajar o mundo para treinar e correr em competições de alto nível técnico.

Diferente das migrações ocorridas entre pessoas que trabalham por vezes nas áreas de serviço a procura das melhores oportunidades de emprego no Brasil $1^{10-11}$, a migração do trabalho esportivo tem sido estudada em diferentes países e contextos socioeconômicos, bem como em diferentes esportes, a partir da visão de que este é um fenômeno que se aproxima do movimento pós-colonial ${ }^{12}$.

As questões teóricas do debate neocolonial compreendem que a migração de atletas advindos de países desfavorecidos economicamente se deslocam para países em que é possível exercer suas profissōes em um bom nível técnico ${ }^{13}$. Consideramos que na medida em que o Brasil surge no cenário internacional como país emergente (fazemos parte do badalado BRICS, onde se incluem Rússia, China, Índia e África do Sul), o país passa a ser também rota de escolha para que diversos atletas pensem em passar períodos aqui treinando e competindo atrás de boas premiações e visibilidade. Afinal, o país vive num estado democrático, funciona com instituições jurídicas sólidas, tem uma moeda estável e também será sede dos dois maiores eventos esportivos do mundo nos próximos anos.

As bases econômicas desfavoráveis e a farta mãode-obra qualificada permitem que diversos atletas 
sejam enviados ou sintam-se impelidos a sair de seus países. MAGUIRE ${ }^{14}$ relaciona as bases da política econômica do futebol e o desenvolvimento de países fornecedores de mão de obra qualificada e relativamente acessível, incluindo Brasil e Argentina, como países agentes deste processo ${ }^{14}$.

De forma contrária, mas que nos ajudam a pensar em no nosso objeto de pesquisa, verifica-se que no atletismo as regiôes da África supracitadas fornecem grande quantidade de corredores com alto nível técnico, visto que os fatores geográficos, sociais e psicológicos favorecem o surgimento de diversos atletas de corrida ${ }^{15}$.

Em relação ao nacionalismo, as ideologias construídas durante a formação dos Estados-Nação e seus símbolos foram ao longo do tempo sendo construídas a partir das tensões étnicas, de gênero, raça e religião, entre outras. Nações são territórios construídos por pessoas a partir das suas contradiçôes, preconceitos e princípios de comunidades imaginadas ${ }^{16}$.

Os sentimentos de pertencimento são negociados no cotidiano e por isso mesmo são fluidos em que as tensōes se dão entre as diferenças, a partir do reconhecimento entre os de "dentro" e os de "fora". Identidade nestes termos envolvem questôes de representação, nostalgia, mitologia e tradição a partir da construção dos estados nacionais ${ }^{16-17}$.

A lógica neste mercado opera a partir das contradiçôes colocadas por LOVISOLO ${ }^{18}$ em que existem as explicaçōes universalistas e as regionalistas para o desenvolvimento do esporte globalizado. Enquanto o primeiro se desenvolve na lógica dos grupos que compreendem a mercadorização do esporte e seu desenvolvimento voltado para o lucro, o segundo está arraigado nos pensamentos de proteção e defesas das práticas locais. Acreditamos que ao tomarmos às restrições impostas pela CBAt como exemplo para compreendermos como este mercado funciona, contribuímos com pesquisas que mostram como estas tensões escritas por LOVISOLO ${ }^{18}$ ainda estão em funcionamento no campo esportivo.

Em nosso país o atletismo está intimamente ligado às camadas mais populares da sociedade, a ponto de, nos últimos anos, estar sendo patrocinado exclusivamente por um banco cujo maior acionista é o governo federal. Tais questōes permitem inferir que seja razoável que as premiaçōes devam incentivar atletas formados no país, visto que há recursos governamentais no pagamento de salários, bolsas, ajudas de custo e patrocínio para realização das competições.

Ao criar cotas de participação para estrangeiros, escolhe-se como tentativa de solução a forma "mais caseira”, ou seja, impor limites aos que são de fora. Além disso, em última circunstância, patrocinadores brasileiros e a mídia local tendem a ter dificuldade em apoiar brasileiros que não estão entre os melhores, mesmo que as competições sejam eminentemente de caráter nacional.

As razões para estes atletas estrangeiros estarem treinando e competindo no Brasil parecem serem as mesmas encontradas em nosso cotidiano esportivo: forças do mercado que impulsionam atletas que precisam ganhar a vida de modo profissional. Além, é claro, de enviar para os seus parentes parte de seus ganhos. Como exemplo, Stephen Cherono (duas vezes campeão do mundo e recordista mundial dos 3.000 metros) tem a responsabilidade de prover o sustento de cerca de 50 membros de sua família ${ }^{17}$.

Em nossa pesquisa entendemos que os atletas estrangeiros que participam destas competiçóes no Brasil seguem características sociais, culturais e econômicas múltiplas, não havendo um único motivo determinante que os faça migrar para trabalhar em nosso país. Pesquisas nesta área devem estar atreladas a compreensão de

a preliminary typology of sports labor migration encompassing pioneers, settlers, returnees, mercenaries, and nomadic cosmopolitans. This provisional ideal-type framework captures the variable breadth and intensity of the movements and experiences associated with sports labor migration. Sports migrants' encounters, then, are diverse and shaped by differing pressures, rewards, and interdependencies. Crucially, migration is patterned by the interplay of economic, political, historical, geographical, social, and cultural factors ${ }^{19}$ (p.138).

Os atletas de corrida de rua estrangeiros que chegam ao Brasil tendem a encontrar um campo interessante de possibilidades de trabalho: inúmeras provas de rua com nível técnico razoável e com boas possibilidades de se obter colocações de destaque. Como também chegam com mais experiência internacional que os atletas brasileiros, tendem logo a se destacar. Abre-se, portanto, a possibilidade de em um curto período de tempo conseguirem lograr êxito durante o período de estadia em terras tupiniquins.

Além disso, o rendimento físico individual transformado em bons tempos vai permitir, por exemplo, o convite para participação nas melhores provas chancelas pela IAAF, com os melhores prêmios e com boa visibilidade midiática. Neste sentido, o contato com treinadores e federações de diversos países que convidam o atleta a treinar e competir em um determinado país passa a ser interessante para todos aqueles que querem que o nível técnico da sua competição 
seja aumentado, sem se preocupar com a questão da origem deste atleta. Elevar o nível técnico das competiçōes é visto, de modo geral, como o caminho para o desenvolvimento dos atletas nacionais.

Contudo, as movimentações são transitórias e dependem do calendário do circuito anual das provas chanceladas pela IAAF e do nível técnico do corredor ou ainda da forma física que o atleta está vivendo naquele momento. No ano de 2011, por exemplo, foram oficializadas pela CBAt 186 corridas de rua no circuito regional no Brasil, com distâncias variando em média de 5 a $10 \mathrm{~km}$. Para o circuito nacional identificamos 41 provas registradas, com distâncias variando, em sua maioria, de meia maratona até maratona ${ }^{\mathrm{d}}$.

\section{As restrições aos atletas estrangeiros no Brasil}

A participação de atletas estrangeiros em competições esportivas no Brasil está sob Regulação Normativa número $69^{20}$. Nela encontra-se a possibilidade de um atleta estrangeiro ter seu visto classificado como turista, caso este venha a permanecer temporariamente no país e desde que seja explicitamente convidado pelos organizadores. Diz a norma em seu Artigo $5^{\circ}$ parágrafo único:

A solicitação de visto de que trata este artigo será feita diretamente pelo interessado à Repartição Consular brasileira com jurisdição sobre o local de residência do interessado, com apresentação de carta-convite dos organizadores do evento e demais documentos pertinentes à solicitação de visto de turista ${ }^{20}$.

Ressaltamos este ato normativo, pois verificamos que este é um dos pontos destacados por técnicos e dirigentes esportivos do atletismo quando fomos coletar os dados iniciais para nossa pesquisa. Percebemos que dependendo do posicionamento das pessoas envolvidas neste espaço, a norma é citada como um dos pontos de conflito e divergência, colocando em lados opostos interesses financeiros e políticos de grupos que trabalham ou não com atletas de corrida estrangeiros. De forma global, existe a contraposição entre os interesses de proteção do mercado nacional de trabalho e os interesses de melhoria no desenvolvimento do esporte. Neste sentido, a norma passa a ser um divisor de águas nas corridas de rua no Brasil, pois regula o trabalho de atletas, bem como a impossibilidade dos técnicos que os treinam colocar mais atletas nas competiçôese .

Outra norma que também passa a ser ponto de polêmica entre treinadores foi emitida no ano de 2009 pela Confederação Brasileira de Atletismo $(\mathrm{CBAt})^{21} \mathrm{em}$ relação à restrição da presença de atletas estrangeiros em corridas oficiais chanceladas por esta confederaçãof. Esta norma está em conformidade com os ditames da IAAF, na tentativa de regular o fluxo de atletas que venham a treinar e competir nos países afiliados.
Segundo a Norma 09, artigo 7\%:

A participação de atletas estrangeiros em eventos de rua, cross-country, de montanha e em praia será realizada conforme abaixo:

e) Corridas de Rua: as quantidades limite de atletas estrangeiros são as seguintes, observadas as Normas para Reconhecimento e Homologação de Corridas de Rua da CBAt:

- Corrida de Rua Classe A-1 - Nacional: até 3 (três) atletas por país no masculino e 3 (três) atletas no feminino.

- Corrida de Rua Classe A-2 - Nacional: até 2 (dois) atletas por país no masculino e 2 (duas) atletas no feminino.

- Corrida de Rua Classe B - Estadual: até 1 (um) atleta por país no masculino e 1 (uma) atleta no feminino.

As consequências imediatas da Norma 09 são a limitação de atletas estrangeiros nestas competições, fazendo com que as provas com menos visibilidade e premiações sejam resguardadas destes atletas, tendendo, portanto, a preservar os atletas nacionais de uma possível entrada de estrangeiros que são vistos como potenciais ganhadores destas provas. A norma possui uma intenção protecionista, pois impede que muitos estrangeiros estejam em muitas provas e consequentemente não obtenham, por exemplo, a possibilidade de existir um prova que os estrangeiros venham ocupar as 10 primeiras colocações.

A norma que vigora tem o objetivo explicito de impedir que muitos atletas de elite estrangeiros tenham destaque nas competições. Ressaltamos a questão dos atletas de elite na Norma 09 artigo 08 que afirma que

A participação de estrangeiros em corridas de rua que, comprovadamente, não disputem competições de Atletismo de maneira formal, em seus países de origem, poderá ser aceita mediante inscrição normal na prova, sem qualquer direito a tratamento diferenciado ou largar nos pelotôes de elite, devendo 
o organizador consultar a CBAt para comprovação do aqui disposto.

Ora, ser corredor que participa do pelotão de elite significa poder ter o direito de estar em um seleto grupo de corredores que larga em posicionamento destacado dos demais corredores. Ou seja, se o corredor não for de elite não haverá fator limitador em relação à nacionalidade segundo a regra estudada. Porém, sabemos que para obter os melhores resultados em competiçôes de rua, que por vezes chegam a ter cerca de 5.000 inscritos por competição, é necessário que o atleta tenha uma boa posição na hora da largada se quiser almejar um lugar no pódio. Some-se a isso o fato de que provas chanceladas pela a IAAF e sua filiada no Brasil a CBAt, servem para que os atletas tenham seus tempos oficializados e ranqueados. Com esses tempos oficializados os atletas podem obter patrocínios, convites para outras competiçóes de alta visibilidade e correr entre o pelotão das demais provas de elite de rua, tanto no Brasil quanto em outros países.

Impedir a participação no pelotão de elite significa quase que impedir a possibilidade do atleta estrangeiro fazer um bom tempo em uma corrida de rua ${ }^{\mathrm{h}}$.
Para termos um exemplo de como funciona a operacionalização da restrição nas competições, é mandatório que os organizadores dos eventos de rua no Brasil devem também enviar à CBAt a cópia do convite feito ao corredor estrangeiro, além de apresentarem também a autorização da federação do país de origem deste atleta. Apenas 28 atletas estrangeiros estavam autorizados pela CBAt a competir em corridas de rua no Brasil ao longo de 2012. Destes, 19 são de nacionalidade queniana, três tanzanianos, três etíopes, um holandês, um marroquino e um portuguêsi. Inferimos que este tipo de burocracia tende a afastar das competições atletas que não estejam em contato com suas federações e que os seus técnicos no Brasil tenham pouco contato com os organizadores do eventoj. Além disso, o "ranking" da confederação que tem como objetivo premiar os melhores corredores anualmente com recursos financeiros que variam de $\mathrm{R} \$ 3.000,00$ (para o terceiro lugar geral do "ranking" num total de 29 etapas) a $\mathrm{R} \$ 10.000,00$ (para o primeiro lugar) apenas permite que atletas brasileiros natos ou naturalizados participem deste tipo de premiação ${ }^{k}$.

\section{Método}

Essa pesquisa é de natureza qualitativa e adota uma abordagem crítica em relação à fala dos atores sociais envolvidos. A população deste estudo é composta de técnicos brasileiros que treinam atletas brasileiros e estrangeiros e atualmente participam de competições em nível nacional e internacional. Utilizamos como técnica de coleta de dados a entrevista com roteiro semi-estruturado de perguntas. $\mathrm{O}$ roteiro foi aprovado por um grupo de especialistas, todos doutores na área de pesquisal.

Esta pesquisa foi aprovada pelo Comitê de Ética da IES dos pesquisadores, não havendo nenhum conflito de interesse em sua realizaçãa ${ }^{\mathrm{m}}$. Todos os entrevistados concordaram com as suas

\section{Resultados e discussão}

$\mathrm{Na}$ pesquisa analisamos a fala dos treinadores de corridas de rua que mantém em suas equipes atletas com nível técnico de destaque, capazes de lutar pelas primeiras posiçōes das provas no Brasil. Os técnicos mantêm ou não atletas estrangeiros em suas equipes e participaçóes na pesquisa e autorizaram que suas respostas fizessem parte de nosso estudo, a partir da assinatura do Termo de Consentimento Livre e Esclarecido.

Realizamos como amostra intencional a entrevista com 10 técnicos brasileiros com experiências em competiçôes internacionais. A partir deste número de entrevistados percebemos que chegamos a um ponto de saturação de dados, onde se repetiam as falas de nossos pesquisados. Para a elaboração das categorias aplicamos a análise de conteúdo ${ }^{22}$. Todos os participantes assinaram o termo de consentimento livre e esclarecido de nossa pesquisa e não houve conflito de interesses na escolha de nossa amostra.

nossa amostra intencional se dividiu igualmente entre os que são favoráveis a vinda e permanência dos atletas estrangeiros e os que são favoráveis às restriçôes.

Percebemos que o posicionamento de cada técnico está estreitamente relacionando com a presença ou 
não de atletas estrangeiros entre os seus treinados. No caso de técnicos que não tiveram a experiência no treinamento ou não vislumbram treinar atletas estrangeiros seus posicionamentos tendem a ser favoráveis as medidas adotadas pela confederação. Ou seja, as percepçóes se diluem dependendo do lado em que o técnico está: se tem ou teve no grupo estrangeiros é contra a restrição; se não tem ou não confere esta possibilidade é favorável às medidas da CBAt.

Uma das justificativas para a restrição dos estrangeiros nas corridas de rua é que estes virão e irão transformar negativamente o cenário profissional, fazendo com que o atletismo brasileiro fique "em perigo", "não se desenvolva". Para os técnicos contrários às restrições há o entendimento que isto só demonstra a fragilidade técnica e profissional do nível do atletismo brasileiro, pois acaba por não colocar os melhores competindo.

$\mathrm{Na}$ fala dos nossos entrevistados:

eu fico triste porque isso tira chance de brasileiros

de se destacarem, de aparecerem mais... (T2) (Grifo nosso).

A vinda dos quenianos é bom para aumentar o nível dos atletas de ponta. Mas o que me preocupa são os atletas juvenis que não vão conseguir enfrentar os quenianos, os marroquinos, os etiopês, $\mathrm{e}$ tanzanianos. Essa é uma questão, eu acho que essa lei deveria ter uma restrição por número total de estrangeiros (T3) (Grifo nosso).

Os direitos são iguais, porque primeiro lá fora não tem restrição, e muitos atletas em muitas modalidades estão fazendo vida milionária em outros países, depois existe a melhora do índice técnico das provas e por último há a melhora dos resultados dos atletas brasileiros em função da competitividade imposta pelos atletas estrangeiros... desvantagem nenhuma... (T5) (Grifo nosso).

Não vejo nenhum problema na participação dos estrangeiros, mas acredito que isto deva mexer com os atletas brasileiros a treinarem mais e os técnicos a se qualificarem melhor (T6) (Grifo nosso).

Os depoimentos dos que são favoráveis às restrições impostas não visualizam a competição com os melhores enquanto caminho de desenvolvimento dos atletas nacionais. De fato, apostam na reserva de mercado como modo de desenvolvimento. Sabemos que a discussão entre protecionistas da reserva nacional e os favoráveis à abertura se manifesta em quase todos os campos, especialmente no econômico. É bem possível que atitudes ou ideologias gerais se tornem orientaçôes também valiosas no campo do esporte.

Para os técnicos que trabalham com os estrangeiros e tem interesse profissional e econômico com este grupo, há o entendimento que esta restrição é desfavorável ao desenvolvimento do nível técnico atletismo brasileiro. Afinal, na maioria das vezes estes técnicos pagam os custos de entrada destes atletas no Brasil, bem como sua estadia e alimentação. Recebem de volta percentuais sobre as premiaçōes ${ }^{\mathrm{n}}$. Para este grupo a entradas principalmente dos africanos só fará bem ao atletismo em terras tupiniquins, porque tiraria o atletismo brasileiro de uma espécie de situação de conforto que este esporte atualmente se encontra, exatamente porque conta com o benefício das limitações impostas aos estrangeiros.

A justificativa para defender ou criticar a norma está pautada sob o guarda chuva do nacionalismo. Ou seja: todos dizem pensar, em última instância, no bem do atletismo nacional.

O fato dos atletas africanos estarem participando das provas de corrida de rua é visto como ponto de tensão entre os técnicos. A percepção é de que a participação destes atletas traz consequências para o desenvolvimento do atletismo como um todo no Brasil. Em algumas falas é como se a presença deles fosse percebida como maléfica, pois propiciaria um entrave no desenvolvimento. Nossos informantes afirmam que

A restrição aos estrangeiros tem que ser pra valer, senão eles vêm aqui, treinam, competem, ganham e vão embora, não deixam nada... dizimam tudo, deixam o esporte arrasado.... (T9) (Grifo nosso).

Acho que tem que ter africano sim, mas do jeito que está virou festa. Eu estive na Confederação Brasileira, no início do ano passado e eles prometeram que essa invasão africana não ia acontecer, mas foi a mesma coisa se eu falasse para os africanos virem todos para o Brasil. E eles estão em peso morando no Brasil, no Paraná e em Taubaté, (...) tem que ter africanos, mas não dessa maneira. Então eu acho que tem que restringir. A África é um continente e a CBAt falou que são 13 por país, mas a CBAt esqueceu que a África é um continente, que tem 54 países, e desses 54 , tem uns 20 que são os tops do atletismo, entre eles, Marrocos, Tanzânia, Etiópia, Quênia, esse pessoal esta invadindo aqui. Mas volto a dizer, tem que ter africano, mas não do jeito que está (T8) (Grifo nosso).

Os quenianos estáo abraçando o mundo todo, se não me engano em 2007 dos 400 primeiros colocados 12 apenas não eram quenianos. No ano passado dos 
30 colocados da maratona só 1 atleta não era queniano, que era exatamente um brasileiro o Marílson, quando chegou perto do fim do ano fechou da seguinte forma: dos 24 primeiros colocados todos eram quenianos exceto o Marílson (T10) (Grifo nosso).

Nossa condição técnica só melhora competindo com estrangeiros, alguns treinadores são medíocres e esta mediocridade mostra o medo de competir. Já perdi São Silvestres contra campeões olímpicos e já vencemos São Silvestres contra campeões olímpicos e lideres do ranking internacional. Sou radicalmente contra a não permissão para estrangeiros, visto que na Europa e nos Estados Unidos temos total liberdade para competir. Lutar por prêmios é uma coisa, lutar por performance é outra (T8) (Grifo nosso).

A fala dos entrevistados nos remete aos exploradores que vinham ao Brasil ainda no período da colônia obter, normalmente a força, os recursos desejados e retornarem ao seu país de origem com nossas riquezas. Há no discurso um fundo de imaginário anticolonialista, os atletas são identificados com o tipo de colonizador que leva as riquezas do país. De fato, o colono que as desenvolve não aparece no cálculo. Decorre, então, o apoio à restrição na participação dos estrangeiros, identificando-se como um grupo coeso, de uma comunidade imaginada.

Por outro lado, na fala do técnico contrário à restrição, se compreende que os brasileiros é que estão restringindo o mercado de trabalho de outros atletas de corrida de rua e que em outros centros esportivos, tais como a Europa e os EUA tal fato não ocorre, o que nos leva a inferir que a restrição tende a ser o caminho mais curto para não expor os atletas brasileiros a resultados insatisfatórios, como se eles precisassem ser protegidos via legal.

A fala do técnico oito (T8) beira a provocação na medida em que qualifica os técnicos brasileiros favoráveis à restrição de medíocres, e há também uma interpretação de que estes são mercenários, pois como visto na última frase, os técnicos estariam mais preocupados com os valores financeiros envolvidos nestas competições do que uma preocupação em melhorar o tempo de seus atletas.

Em relação aos africanos nas provas

Os africanos já saem da barriga da mãe correndo,vai pra escola correndo,vai para o cinema correndo, então quando tem olheiro no futebol, os agentes aqui do Brasil vão ao Quênia, e olha que covardia, trazem uma remessa de africanos, eles ficam aqui três meses com visto de turista, e no meu modo de ver é errado, porque eles estão trabalhando, estão correndo, e o visto turístico não permite isso, então ficam três meses aqui, depois volta pro Quênia e depois trazem mais uma legião com hemoglobina e o pulmão cheio, lá em cima. É uma covardia, os africanos chegam aqui no Brasil bala na agulha, a hemoglobina lá em cima, então realmente é muito difícil enfrentar os africanos (T7) (Grifo nosso).

os técnicos e atletas não querem melhorar e sim ganhar. Mas para ganhar e pensar em resultados de alto nível tem que competir com quem tem alto nível e quem pensa assim... esquece... nunca.

Como vamos ser representados dignamente numa olimpíada com técnicos e atletas pensam assim? Se não melhoram o nível com atletas que estão aqui facilitando esta oportunidade, o que vai fazer numa olimpíada com atletas ainda melhores? Definitivamente esquece... (T5) (Grifo nosso).

Para o técnico favorável à restrição, os brasileiros não têm condições técnicas de superar os estrangeiros, chegando a ser, como grifamos covardia. Ora, espera-se que no esporte vença o melhor, mas no caso abordado, o melhor, ou os melhores, não podem participar todos de todas as provas. Neste sentido, algo precisa ser feito para deter estes "superatletas": restringir via legal a entrada e permanência de estrangeiros que possam a vir a prejudicar o trabalho dos brasileiros.

Mas para o técnico de opinião contrária à restrição, é a participação deste grupo de atletas que fará com que brasileiros se tornem mais bem preparados para as competiçóes internacionais. A lógica aqui é que se um atleta quer se destacar entre os melhores do mundo, ele deve ter experiência internacional para então ser reconhecido como, então, um dos melhores do mundo. Ou seja, a sua profissionalização bem como o seu amadurecimento técnico passa por competições fora do Brasil.

A pressão, portanto, por internacionalização das competições de corrida de rua tende a ser cercada de conflitos e interesses, na medida em que o que aparece é uma leve forma de se proteger os trabalhadores do mercado nacional contra os do mercado internacional, mas o que nos parece relevante é que ambos usam a justificativa do desenvolvimento do atletismo brasileiro para defenderem suas posiçôes.

Ao abordarmos a questão da internacionalização esportiva suscitamos discussões sobre como os dirigentes tentam conciliar posiçôes divergentes e que, por vezes, parecem inconciliáveis.

A internacionalização esportiva, assim como outras áreas da internacionalização do trabalho, está 
pautada na tentativa de se proteger os trabalhadores de uma determinada nação, em detrimento do que se considera como aquele que vai "roubar" os empregos deste país, ou seja, o estrangeiro.

Em nosso estudo os atletas considerados estrangeiros são aqueles que mesmo morando em nosso país, são identificados pelos técnicos favoráveis às restrições como pessoas que tendem a ficar por pouco tempo, apenas treinando durante um período específico e que também estão a procura de recursos financeiros e visibilidade sem nenhum compromisso com o desenvolvimento do esporte.

Entre a internacionalização (necessária para o desenvolvimento técnico) e a proteção de mercado (necessária para salvaguardar os atletas brasileiros) ficamos com o argumento de que se o atletismo brasileiro estivesse num patamar técnico acima do que se encontra hoje, não teríamos este tipo de restrição legal imposta por seus dirigentes, visto que os estrangeiros não representariam uma "ameaça".

Compreender o fenômeno do fluxo migratório do trabalho esportivo ao redor do mundo nos ajuda a entender este dinâmico mercado. Como opera, quais as tensões, discursos e justificativas sobre regular ou não a entrada e participação de atletas estrangeiros em nosso país. Um esporte individual como atletismo que funciona à margem da identidade clubística, parece estar operando por parte de seus protagonistas sob o guarda chuva protetor do nacionalismo ${ }^{16}$.

O atleta local deve ser defendido mediante a reserva do mercado, isto é, da participação nos eventos esportivos que garanta a ele uma chance entre os estrangeiros, quer seja eliminando a concorrência, quer seja criando uma premiação específica.

As políticas públicas de desenvolvimento esportivo no Brasil ainda estão focadas nos resultados, principalmente nos atletas de ponta ${ }^{\circ}$. Investimentos em educação e qualidade técnica dos treinamentos também poderiam ser incorporados, visto que a vida profissional de atletas de alto nível é curta, mas a experiência sobre tais vivências é rica e poderia ser aproveitada de uma forma mais positiva em nosso país. O exemplo do ex-atleta Joaquim Cruz é simbólico nesta questãop

$\mathrm{Na}$ medida em que nossa economia permaneça estável, em desenvolvimento e com uma moeda valorizada, o destaque na mídia internacional sobre o Brasil tende a crescer. O efeito dos megaeventos esportivos também se fará sentir. $\mathrm{O}$ conjunto de fatores pode elevar as pressões migratórias de atletas estrangeiros para o Brasil em vários esportes e não apenas nas corridas de rua. É possível que as forças a favor da abertura do mercado profissional esportivo se confrontem com as que se inclinam pela proteção e reserva enquanto caminho de desenvolvimento do esporte nacional.

Desde a abertura econômica realizada no início da década de 90 nosso país tem se transformado muito. A entrada de empresas estrangeiras teve como consequência a vinda de um capital humano especializado para trabalhar e consequentemente competir por vagas de emprego com os que aqui estão. Este fluxo de estrangeiros permitiu uma interação e serviu, em última análise para aumentar a competitividade em um país que tinha sérios problemas de reserva de mercado, tais como nos setores de informática e automobilismo ${ }^{23}$.

Compreender o atleta estrangeiro como um perigo, uma ameaça aos atletas nacionais parece não ser a solução. O esporte reforça a identidade nacionalista, mas usá-la com desculpa para proteger um mercado nacional não parece contar com viabilidade a médio e longo prazo. Ao sediar competiçōes internacionais, as delegaçōes nacionais terão que provavelmente passar pelo dissabor de não subir ao pódio com tanta frequência, sobretudo depois da campanha olímpica de Londres 2012, em que nenhum atleta brasileiro subiu ao pódio nesta modalidade esportiva.

Estudos futuros podem revelar como pensam estes atletas estrangeiros em relação aos treinos e competições realizadas no Brasil. Como exemplo, mostramos a fala de um atleta estrangeiro de alto nível que vem constantemente ao Brasil:

Eu venho para cá, corro uma maratona, tenho que voltar pro Quênia, esperar 3 meses, treinar, pra voltar a competir aqui. Eu acho realmente que o Quênia é o melhor país para se treinar, porque muitos preferem altitudes elevadas e quando você treina em altitudes e não no nível do mar, por exemplo, ocorre uma melhora na sua performance. (Atleta africano).

No discurso do atleta as normas aparecem gerando a não permanência, embora a condição técnica da altitude tenha um peso considerável na decisão de voltar para o pais de origem, no caso, Quênia. O Brasil tem experiência com o treinamento de altura já desde a Copa de $1970^{q}$. A questão que surge é sobre as possibilidades de favorecer o treinamento dos atletas em altura condizentes como os efeitos aeróbios esperados. É provável que este e outros atletas estrangeiros façam o mesmo em outros países de passar poucos dias em cada país, competindo ao redor do mundo nas principais provas. 
A análise realizada na pesquisa deixa uma questão em aberto: até que ponto as justificativas de nacionalismo irão se pautar nas restriçôes ou abertura de mercados frente às pressôes por internacionalização e movimentação migratória no esporte brasileiro?

\section{Notas}

a. Corridas de rua tendem a separar os atletas amadores por tempo na hora da largada, formando as baterias de largada pelo tempo dos corredores. Para os atletas com melhor tempo, os organizadores reservam o espaço conhecido como "tempo Quênia" próximo aos corredores de elite.

b. Cf. Revista Runner's World Brasil, outubro de 2009.

c. Alguns exemplos só no grande Rio de Janeiro: Circuito Atenas de Corridas de Rua; Circuito Adidas de Corrida de Rua; Circuito Rio Antigo; Circuito Vênus (exclusivamente feminino); Circuito Meia Maratona Faz um 21, entre outros.

d. Cf. www.cbat.org.br. Acesso em: 20 dez. 2011.

e. Não raro esta norma foi citada nos primeiros contatos com técnicos e dirigentes em conjunto com a norma da CBAt de 2009 para justificar a não participação de atletas africanos nas corridas de rua chancelas pela CBAt.

f. Trocas de acusaçôes são frequentes pela mídia e a competência dos atletas e técnicos brasileiros não raro são colocados à prova para aqueles que são contra as restriçôes impostas pela CBAt. Cf. www.terra.com.br. Acesso em: 24 maio 2012.

g. Assim como os agentes FIFA, a IAAF criou em 2012 um sistema regulatório de Representante dos atletas de alto nível, o conhecido TOP-30. Cf. www.iaaf.org. Acesso em: 25 maio 2012.

h. Não por acaso algumas destas competições chegam a cobrar de atletas amadores valores de inscrição que podem custar cinco vezes mais, se estes quiserem participar deste grupo de elite, largando na frente dos demais competidores.

i. Cf. www.cbat.org.br. Acesso em: 15 jan. 2012.

j. Como exemplo, a Corrida da Ponte, realizada entre as cidades de Niterói e Rio de Janeiro no ano de 2012 contou com um dos locutores que dizia durante o aquecimento para a prova: "tem atleta de fora hoje aqui, mas a gente não vai deixar eles botarem água no nosso chope nem deixar eles subirem no pódio”.

k. Cf. www.cbat.org.br. Acesso em: 5 fev. 2012.

1. Como ajuda para nossa análise contamos com registro em caderno de campo para ajudar nas observaçôes realizadas durante as entrevistas, feitas nos locais de treino e competições.

m. O processo de aprovação obteve o ${ }^{\circ} 07519622.0 .0000 .5287$.

n. Cf. http://www.temporun.com.br/news.asp?id=14. Acesso em: 5 jun. 2012.

o. Ver por exemplo a distribuição dos recursos do Bolsa Atleta do Governo Federal.

p. Medalhista de ouro nas Olimpíadas de Los Angeles em 1984, trabalha atualmente com atletismo nos E.U.A.

q. Ver a análise de Salvador e Soares sobre a Copa de 1970 e a participação especial do Prof. Lamartine DaCosta em sua implementação ${ }^{24}$.

\section{Abstract}

There is a Kenyan in our race: athletics and migration in Brazil

The main purpose of this study was to analyze the migratory tendencies of foreign long distance runners, especially those from African descent. This interest rises from the great success these athletes have displayed in all major Brazilian city running events. The analysis was focused on coaches who work with Brazilian and international long distance runners. Coaches who are involved with training international runners are against to the regulation that restricts the participation of foreign runners in competitions organized by the Brazilian confederation (CBAt). On the other hand, coaches who work with Brazilian runners are in agreement with these rules. In conclusion we found that in an individual sport such as running that operates outside of traditional sports clubs there are tendencies of nationalism protecting the local athlete and discriminating the international competitor.

KEY WORDS: Athletics; Migration; Nationalism. 


\section{Referências}

1. Dustmann C, Bentolila S, Faini R. Return migration: the European experience. Econ Policy. 1996;11: 213-50.

2. Hoberman J. Darwin's athletes: how sport has damaged Black America and preserved the mith of race. New York: Houghton Mufflin; 1997.

3. Rial CS. Futebolistas brasileiros na Espanha: emigrantes porém... Rev Dialect Trad Pop. 2006;41:163-90.

4. Damo A. Do dom a profissão: uma etnografia do futebol de espetáculo a partir da formação de jogadores no Brasil e na França. São Paulo: Aderaldo \& Rothchild; 2007.

5. Soares AJ, Melo L, Costa F, Bartholo T, Bento J. Jogadores de futebol no Brasil: mercado, formação de atletas e escola. Rev. Bras. Ciênc. Esporte. 2011;33:905-921.

6. CBAt. Confederação Brasileira de Atletismo. Base de dados: 2011. [citado 12 dez. 2011]. Disponível em: <http:// www.cbat.org.br.>.

7 FPA. Federação Paulista de Atletismo. Departamento de corrida de rua. Banco de dados. [citado 27 jun 2008].

8 CBAt. Confederação Brasileira de Atletismo. Base de Dados. 2008. [citado 12 dez. 2011]. Disponível em: <http:// www.cbat.org.br.>.

9. Larsen H. Kenyan dominance in distance running: composition biochemical physiological. Oxford: Blackwell; 2003.

10. Cogo D. Mídia, imigração e interculturalidade: mapeando as estratégias de midiatização dos processos migratórios e das falas imigrantes no contexto brasileiro. Front Est Midiáticos. 2002;4:145-63.

11. Golgher A. Fundamentos da migração. Belo Horizonte: UFMG/Cedeplar; 2004.

12. Young R. Postcolonialism: an historical introduction. Oxford: Blackwell; 2001.

13. Bale J, Cronin M. Sport and postcolonialism. New York: Berg, 2003.

14. Maguire J. Sport labor migration research revisited. J Sport Soc Issues. 2004;28:477-82.

15. Onywera V, Scott R, Boit M, Pitsiladis Y. Demographic characteristics of elite Kenyan endurance runners. J Sport Sci. 2006; 415-22.

16. Anderson B. Comunidades imaginadas: reflexões sobre a origem e a difusão do nacionalismo. São Paulo: Companhia das Letras; 2008.

17. Jarvie G. Sport, culture and society: an introduction. Abingdon: Routledge; 2006.

18. Lovisolo H. Tédio e espetáculo esportivo. In: Alabarces P, organizador. Fútbologías: fútbol, identidad y violencia en América Latina. Buenos Aires: Clacso; 2003. p.241-55.

19. Falcous M, Maguire J. Globetrotters and local heroes? Labor migration, basketball, and local identities'. Soc Sport J. 2005;22:137-57.

20. Brasil, 2006, ato normativo número 69. Conselho nacional de Emigração. Resolução Normativa no 69, de 07/03/2006. [citado 30 mar. 2012]. Disponível em: http://portal.mte.gov.br/trab_estrang/resolucoes-normativas.htm.

21. Confederação Brasileira de Atletismo. Norma 09. [citado 20 maio 2011]. Disponível em: http://www.cbat.org.br/ normas/Norma09.pdf.

22. Bardin L. Análise de conteúdo. Lisboa: Ediçōes 70; 2009.

23. Leitão M. Saga brasileira. Rio de Janeiro: Record; 2011.

24. Salvador MAS, Soares AJG. A memória da copa de 70: esquecimentos e lembranças do futebol na construção da identidade nacional. Campinas: Autores Associados; 2009. v.1.

Recebido para publicação: 28/06/2012

Revisado: 10/03/2013

Aceito: 09/04/2013 24220-330 - Niterói - RJ - BRASIL e-mail: chenriqueribeiro@ig.com.br

.

